Method for Compiling Temporally and Spatially Aggregated Data on Hydraulic Fracturing-Treatments and Wells

Open-File Report 2021-1090 


\section{Method for Compiling Temporally and Spatially Aggregated Data on Hydraulic Fracturing-Treatments and Wells}

By Brian A. Varela and Tanya J. Gallegos

Open-File Report 2021-1090 


\section{U.S. Geological Survey, Reston, Virginia: 2021}

For more information on the USGS - the Federal source for science about the Earth, its natural and living resources, natural hazards, and the environment-visit https://www.usgs.gov or call 1-888-ASK-USGS.

For an overview of USGS information products, including maps, imagery, and publications, visit https://store.usgs.gov.

Any use of trade, firm, or product names is for descriptive purposes only and does not imply endorsement by the U.S. Government.

Although this information product, for the most part, is in the public domain, it also may contain copyrighted materials as noted in the text. Permission to reproduce copyrighted items must be secured from the copyright owner.

Suggested citation:

Varela, B.A., and Gallegos, T.J., 2021, Method for compiling temporally and spatially aggregated data on hydraulic fracturing - Treatments and wells: U.S. Geological Survey Open-File Report 2021-1090, 30 p., https://doi.org/10.3133/ofr20211090.

ISSN 2331-1258 (online) 


\section{Contents}

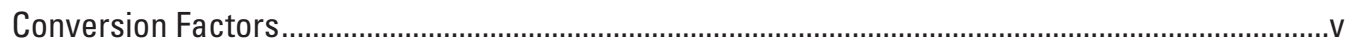

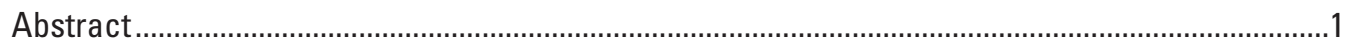

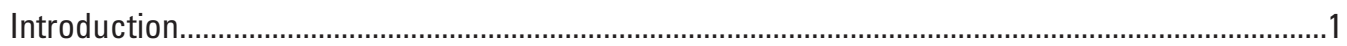

Purpose

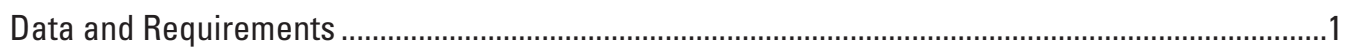

Data on Hydraulically Fractured Oil and Gas Wells ................................................................

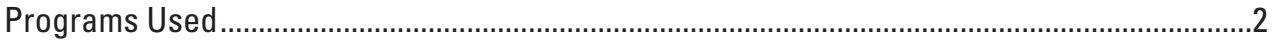

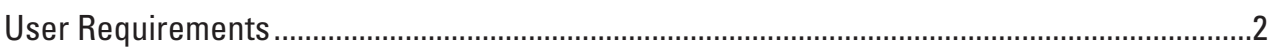

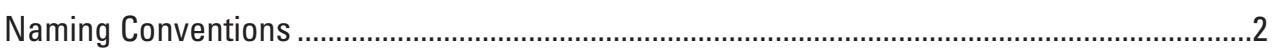

Process Steps

Step 1: Convert treatment amounts .................................................................................

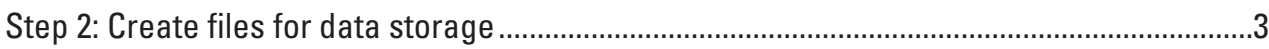

Step 3: Use Microsoft Access to store data from "converted treatments" database and

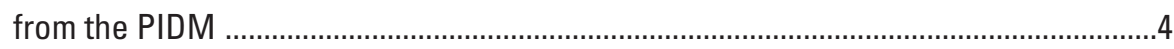

Step 4: Create a master treatment table .............................................................................

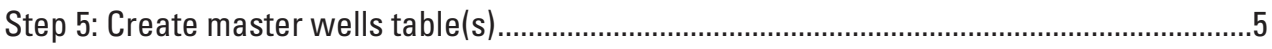

Step 5a: Compile FRAC/REFRAC wells from the PIDM and check ...................................

Step 5b: Compile FRAC/REFRAC onshore wells and check ............................................

Step 5c: Compile FRAC/REFRAC onshore wells completed during the years of interest and check ............................................................................................

Step 5d: Compile FRAC/REFRAC oil and gas onshore wells completed in the years of interest and check .............................................................................................7

Step 5e: Compile FRAC/REFRAC, horizonal, vertical, directional, oil and gas onshore wells completed for year(s) of interest.................................................

Step 5f: Create table(s) of FRAC/REFRAC horizontal, directional, oil and gas onshore wells completed in the year(s) of interest.............................................

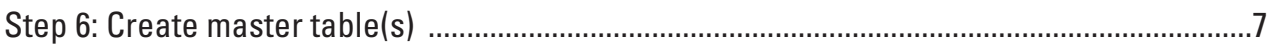

Step 7: Check master table(s) counts ......................................................................................

Step 8: Start the process to compile treatment totals ...............................................................

Step 9: Create master well treatment totals table(s) .............................................................

Step 10: Create a master well treatment total by fluid table(s) ..................................................

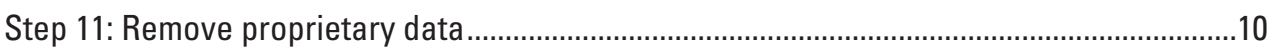

Summary

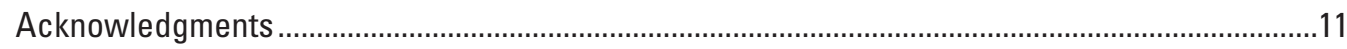

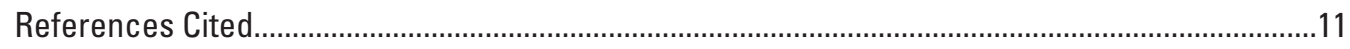

Appendix 1. Java program, “ConvertTreatments" ................................................................14

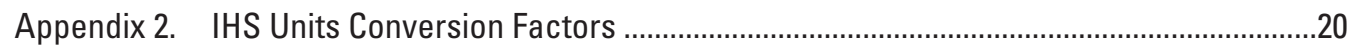

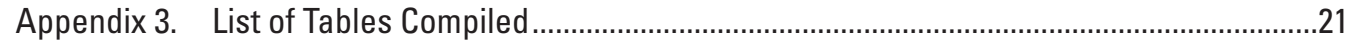

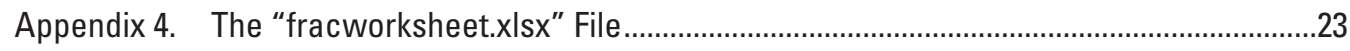




\section{Tables}

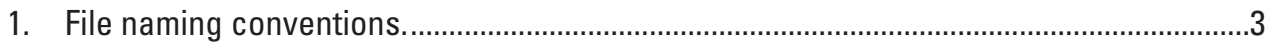

2.1. IHS Markit (IHS Markit, 2019) unit conversion factors ........................................................20

4.1. Step 3 count of treatment records .....................................................................................23

4.2. Step 3 count of TRTM_UNIT records. ..............................................................................23

4.3. Step 3 count of AGENT_UNIT records .................................................................................24

4.4. Step 4 FRAC and REFRAC treatment record counts .....................................................24

4.5. Step 5a unique UWI and Master Well Table-All record counts........................................24

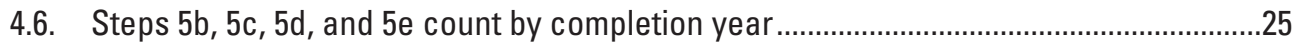

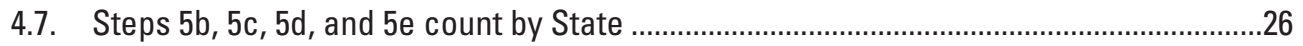

4.8. Steps 5b, 5c, 5d, and 5e count by Final Status ................................................................27

4.9. Steps 5b, 5c, 5d, and 5e count by HOLE_DIRECTION ........................................................28

4.10. Step $5 f$ record counts for land-based oil and gas horizontal, directional and vertical wells

4.11. Step 6 record counts for building Master Table-[start year of interest-end year of interest].

4.12. Step 7 record count of Master Table-[start year of interest-end year of interest] .........29

4.13. Step 8 Master Table-[start year of interest-end year of interest] record count of TRTM UNIT

4.14. Step 9 record counts of unique wells that had treatment amounts ...............................22

4.15. Step 10 record counts of treatment totals by fluid 30 


\section{Conversion Factors}

U.S. customary units to International System of Units

\begin{tabular}{|c|c|c|}
\hline Multiply & By & To obtain \\
\hline \multicolumn{3}{|c|}{ Volume } \\
\hline $\begin{array}{l}\text { barrel (bbl; petroleum, } 1 \text { bar- } \\
\quad \text { rel=42 gal) }\end{array}$ & 0.1590 & cubic meter $\left(\mathrm{m}^{3}\right)$ \\
\hline quart (qt) & 0.9464 & liter (L) \\
\hline gallon (gal) & 3.785 & liter (L) \\
\hline gallon (gal) & 0.003785 & cubic meter $\left(\mathrm{m}^{3}\right)$ \\
\hline gallon (gal) & 3.785 & cubic decimeter $\left(\mathrm{dm}^{3}\right)$ \\
\hline million gallons (Mgal) & 3,785 & cubic meter $\left(\mathrm{m}^{3}\right)$ \\
\hline cubic inch $\left(\right.$ in $\left.^{3}\right)$ & 16.39 & cubic centimeter $\left(\mathrm{cm}^{3}\right)$ \\
\hline cubic inch $\left(\mathrm{in}^{3}\right)$ & 0.01639 & cubic decimeter $\left(\mathrm{dm}^{3}\right)$ \\
\hline cubic inch $\left(\right.$ in $\left.^{3}\right)$ & 0.01639 & liter (L) \\
\hline cubic foot $\left(\mathrm{ft}^{3}\right)$ & 28.32 & cubic decimeter $\left(\mathrm{dm}^{3}\right)$ \\
\hline cubic foot $\left(\mathrm{ft}^{3}\right)$ & 0.02832 & cubic meter $\left(\mathrm{m}^{3}\right)$ \\
\hline cubic yard $\left(\mathrm{yd}^{3}\right)$ & 0.7646 & cubic meter $\left(\mathrm{m}^{3}\right)$ \\
\hline acre-foot (acre-ft) & 1,233 & cubic meter $\left(\mathrm{m}^{3}\right)$ \\
\hline \multicolumn{3}{|c|}{ Mass } \\
\hline pound, avoirdupois (lb) & 0.4536 & kilogram (kg) \\
\hline ton, short $(2,000 \mathrm{lb})$ & 0.9072 & metric ton $(\mathrm{t})$ \\
\hline ton, long $(2,240 \mathrm{lb})$ & 1.016 & metric ton $(\mathrm{t})$ \\
\hline
\end{tabular}

International System of Units to U.S. customary units

\begin{tabular}{|c|c|c|}
\hline Multiply & By & To obtain \\
\hline \multicolumn{3}{|c|}{ Volume } \\
\hline cubic meter $\left(\mathrm{m}^{3}\right)$ & 6.290 & $\begin{array}{l}\text { barrel (bbl; petroleum, } 1 \text { barrel } \\
\quad=42 \text { gal) }\end{array}$ \\
\hline liter (L) & 1.057 & quart (qt) \\
\hline liter $(\mathrm{L})$ & 0.2642 & gallon (gal) \\
\hline cubic meter $\left(\mathrm{m}^{3}\right)$ & 264.2 & gallon (gal) \\
\hline cubic decimeter $\left(\mathrm{dm}^{3}\right)$ & 0.2642 & gallon (gal) \\
\hline cubic meter $\left(\mathrm{m}^{3}\right)$ & 0.0002642 & million gallons (Mgal) \\
\hline cubic decimeter $\left(\mathrm{dm}^{3}\right)$ & 0.03531 & cubic foot $\left(\mathrm{ft}^{3}\right)$ \\
\hline cubic meter $\left(\mathrm{m}^{3}\right)$ & 35.31 & cubic foot $\left(\mathrm{ft}^{3}\right)$ \\
\hline cubic meter $\left(\mathrm{m}^{3}\right)$ & 1.308 & cubic yard $\left(\mathrm{yd}^{3}\right)$ \\
\hline cubic meter $\left(\mathrm{m}^{3}\right)$ & 0.0008107 & acre-foot (acre-ft) \\
\hline \multicolumn{3}{|c|}{ Mass } \\
\hline kilogram (kg) & 2.205 & pound avoirdupois (lb) \\
\hline metric ton $(\mathrm{t})$ & 1.102 & ton, short $(2,000 \mathrm{lb})$ \\
\hline metric ton $(\mathrm{t})$ & 0.9842 & ton, long $(2,240 \mathrm{lb})$ \\
\hline
\end{tabular}




\section{Abbreviations}

$\begin{array}{ll}\text { API } & \text { American Petroleum Institute } \\ \text { BBL } & \text { barrel } \\ \text { CF } & \text { cubic feet } \\ \text { COMP_YEAR } & \text { completion year of well } \\ \text { CUM } & \text { cubic meters } \\ \text { FINAL_STATUS } & \text { code to identify well as either oil or gas well } \\ \text { GAL } & \text { gallon } \\ \text { GEO_PROV } & \text { geologic province of the well } \\ \text { HOLE_DIRECTION } & \text { short name of the orientation of the well borehole } \\ \text { HOLE_DIR_NAME } & \text { long name of the orientation of the well borehole } \\ \text { IHS } & \text { IHS Markit } \\ \text { JDBC } & \text { Java Database Connectivity } \\ \text { LAT } & \text { latitude } \\ \text { LB } & \text { pound } \\ \text { LON or LONG } & \text { longitude } \\ \text { MCF } & \text { thousand cubic feet } \\ \text { MS } & \text { Microsoft } \\ \text { PI_COMP_DATE } & \text { completion date of well } \\ \text { PIDM } & \text { Oracle IHS database (IHS Markit, 2019) } \\ \text { OT } & \text { quart } \\ \text { SPUD_DATE } & \text { date that well was spud } \\ \text { USGS } & \text { U.S. Geological Survey } \\ \text { UWI } & \text { unique well identifier } \\ & \end{array}$




\title{
Method for Compiling Temporally and Spatially Aggregated Data on Hydraulic Fracturing- Treatments and Wells
}

\author{
By Brian A. Varela and Tanya J. Gallegos
}

\section{Abstract}

This report provides a step-by-step method for compiling hydraulic fracturing data in the United States (U.S.) from the IHS Markit, 2019, U.S. Well History and Production Relational Database (IHS Markit, 2019). Data on hydraulically fractured wells include their location (geologic province, State, county), well type (oil or gas), orientation (directional, horizontal, or vertical), spud date, completion date and the hydraulic fracturing treatments, treatment fluids types, treatment fluid volumes, additive types, agent types ("proppants"), and proppant amounts injected. This method also describes how to associate each unique well with the hydraulic fracturing treatments to provide an indication of the total amount of all treatment fluids injected into a well for hydraulic fracturing and the volume of each individual treatment fluid type injected.

\section{Introduction}

Hydraulic fracturing is a well stimulation technique applied to oil and gas wells to enhance the production of oil and gas from low permeability reservoirs (Coleman, 2009; Montgomery and Smith, 2010). The technique involves injecting treatment fluid(s) mixed with a propping agent or "proppant" (such as sand) into a well bore to fracture the host rock and create pathways for the oil and gas to flow to the well bore (Veatch, 1983a, b; Ground Water Protection Council and ALL Consulting, 2009; Montgomery and Smith, 2010). Treatment fluids contain a base fluid (such as water, gel, or oil) that is amended with various chemicals or additives, depending on the properties of the target hydrocarbon, reservoir, and the desired fracture geometry (Economides and Nolte, 2000; Elbel and Britt, 2000; Gulbis and Hodge, 2000; U.S. Environmental Protection Agency, 2004; Holditch, 2007). Hydraulic fracturing has historically been applied to wells of a vertical, directional, or horizontal orientation (Ground Water Protection Council and ALL Consulting, 2009). Data regarding these aspects of hydraulically fractured wells and their treatments are found in the IHS Markit, 2019, U.S. Well History and Production Relational Database (IHS Markit, 2019). Several processing steps are needed to both extract the pertinent data and link the hydraulically fracturing wells to their associated hydraulic fracturing treatments.

\section{Purpose}

The purpose of this report is to provide a step-by-step method for compiling data from the IHS Markit, 2019, U.S. Well History and Production Relational Database (IHS Markit, 2019) in a consistent and repeatable manner to achieve data that describe the quantifiable aspects of hydraulic fracturing. The well data are compiled according to their location (geologic province, State, county), well type (oil or gas) and orientation (directional, horizontal, or vertical), spud date, and completion date. The wells are also associated with hydraulic fracturing treatments, treatment fluids type, treatment fluid volumes, additive types, agent types ("proppants"), and proppant amounts used for hydraulic fracturing as defined by IHS Markit (2019). Original data are proprietary and are not provided here but are available through IHS Markit (2019).

\section{Data and Requirements}

\section{Data on Hydraulically Fractured Oil and Gas Wells}

Data are from the IHS Markit (IHS), U.S. Well History and Production Relational Database (see http://www.ihsenergy.com) (IHS Markit, 2019). IHS currently offers two versions of this database, an online version (Enerdeq) and a local Oracle IHS database (PIDM) based on a PIDM data model (referred to as "PIDM" in this report) (IHS Markit, 2019). This report is written for the local Oracle version (based on PIDM Data Model 2.5.3 released February 2012) because it 
matches standards defined for petroleum industry databases (IHS Markit, 2019). Tabular data include the following:

- Tables WELL and WELL TREATMENT

- Code tables R_FINAL_STATUS, R_ADDITIVE TYPE, COUNTY, GEOLOGIC PROV, PROPPANT TYPE, PROVINCE STATE, TREATMENT FLUID, TREATMENT_TYPE, and WELL_PROFILE_TYPE.

\section{Programs Used}

- Microsoft (MS) Access 2010, released June 5, 2010 (see https://products.office.com/en-US/);

- Microsoft Excel 2010, released June 5, 2010 (see https://products.office.com/en-US/); and

- Java Development Kit (JDK) version 8, released March 2014 (see https://www.oracle.com/technetwork/ java/javase/downloads/jdk8-downloads-2133151.html).

\section{User Requirements}

The user of the method described herein requires access to the IHS Markit (IHS), U.S. Well History and Production Relational Database (IHS Markit, 2019). The user also must have the ability to connect to an Oracle database directly using Java Database Connectivity (JDBC). The use of this method requires an understanding of programming, and specifically, the ability to compile and run a Java program. The user should also understand relational databases, most notably, the relationships between tables and the structure of the Oracle IHS database (PIDM) (IHS Markit, 2019). Finally, the user should be proficient in Microsoft (MS) Office products such as Access, Excel, and Word.

\section{Naming Conventions}

Terms from the PIDM are set in all capital letters; PIDM table names are capitalized and underlined (for example, WELL_TREATMENT); schemas are capitalized, italicized, and underlined (for example, PI CODES); IHS field names (column headings) are capitalized (for example, TRTM_UNIT); and table entries (values) are capitalized and italicized (for example, $G A L$ ) (table 1). Filenames created using this method are in quotation marks (for example, "fracworksheet.xlsx"). MS Access filenames are in bold and in quotes (for example, “master tables.accdb"), table names within MS Access database files are bold and underlined (for example, Master Treatment), query names within MS Access are italicized, bold and underlined (for example, Treatments w codes), field names within MS Access tables are all capitalized and bold (for example, UWI), and table entries within MS tables are all capitalized, bold, and italicized (for example, $\boldsymbol{G A S}$ $\boldsymbol{W E} \boldsymbol{L} \boldsymbol{L})$. Also, when creating MS Access files, we use "[vintage year of PIDM]" and "[start date of compilation]" to indicate the year of the PIDM release and date that the data compilation was started, respectively. Since this process can be used for a single year or groups of multiple years, we use "[start year of interest - end year of interest]" when naming tables or queries and use "year(s) of interest" when referring to all the different groupings of years (for example, "for each year(s) of interest, create a new table called Table Example[start year of interest-end year of interestl"). This is only a concern from step 5 onward. It should also be noted that users must modify many of the "checks" in the "fracworksheet.xlsx" file if this method is used to compile multiple year groupings. 
Table 1. File naming conventions. [IHS, IHS Markit (IHS Markit, 2019); MS, Microsoft; PIDM, Oracle IHS database (IHS Markit, 2019)]

\begin{tabular}{|c|c|c|c|c|c|c|}
\hline Item & Capitalized & Underlined & Italicized & Quotation marks & Bold & Example \\
\hline Terms from PIDM & $\mathrm{X}$ & & & & & PIDM \\
\hline IHS table name & $\mathrm{X}$ & $\mathrm{X}$ & & & & WELL TREATMENT \\
\hline Schemas & $\mathrm{X}$ & $\mathrm{X}$ & $\mathrm{X}$ & & & PI_CODES \\
\hline $\begin{array}{l}\text { IHS field names (column } \\
\text { headings) }\end{array}$ & $\mathrm{X}$ & & & & & TRTM_UNIT \\
\hline Table entries (values) & $\mathrm{X}$ & & $\mathrm{X}$ & & & $G A L$ \\
\hline Filenames & & & & $\mathrm{X}$ & & "fracworksheet.xlsx" \\
\hline MS Access filenames & & & & $\mathrm{X}$ & $\mathrm{X}$ & "master tables.accdb" \\
\hline $\begin{array}{l}\text { Table names within } \\
\text { MS access }\end{array}$ & & $\mathrm{X}$ & & & $\mathrm{x}$ & $\underline{\text { Master Treatment }}$ \\
\hline $\begin{array}{l}\text { Query names within } \\
\text { MS Access }\end{array}$ & & $\mathrm{X}$ & $\mathrm{X}$ & & $\mathrm{X}$ & $\underline{\text { Treatments } w \text { codes }}$ \\
\hline $\begin{array}{l}\text { Field names within } \\
\text { MS Access tables }\end{array}$ & $\mathrm{X}$ & & & & $\mathrm{X}$ & UWI \\
\hline $\begin{array}{c}\text { Table entries within } \\
\text { MS Access table }\end{array}$ & $\mathrm{X}$ & & $\mathrm{X}$ & & $\mathrm{X}$ & GAS WELL \\
\hline
\end{tabular}

\section{Process Steps}

\section{Step 1: Convert treatment amounts}

Use the Java program, "ConvertTreatments" (appendix 1) to convert the various treatment units (TRTM UNIT) including $G A L$ (gallon), $Q T$ (quart), $B B L$ (barrel), $\overline{C F}$ (cubic feet) and $M C F$ (thousand cubic feet) into $C U M$ (cubic meters) as well as to convert proppant amounts (AGENT_UNIT) from $T O N$ (tons) into $L B$ (pounds). Convert units for all records within the IHS WELL_TREATMENT table that have a value for either the treatment fluid amount (TRTM_AMOUNT) or the proppant amount (AGENT_AMOUNT). Only convert units that have a conversion factor in the PIDM (see appendix 2 for a list of IHS unit conversion factors) (IHS Markit, 2019); all other units will be ignored.

\section{Step 2: Create files for data storage}

- Create a new Microsoft (MS) Access file called "HydroFRAC-[vintage year of PIDM]-ConvertedTreatments-[start date of compilation].accdb".

- From here forward "HydroFRAC-[vintage year of PIDM]-ConvertedTreatments-[start date of compilation].accdb" will be referred to as "converted treatments.accdb".

- The output data could be stored in either a single MS Access file or in multiple MS Access files, depending on size limitations. If multiple files are used, then additional filenames should be consecutively numbered and appended with the "file number of total number of files" (for example, "HydroFRAC-[vintage year of PIDM]MasterTables-[start date of compilation]-1 of 2.accdb").

- Create a MS Access file called "HydroFRAC[vintage year of PIDM]-MasterTables-[start date of compilation].accdb".

- From here forward "HydroFRAC-[vintage year of PIDM]-MasterTables-[start date of compilation].accdb" will be referred to as "master tables.accdb".

- The output data could be stored in either a single MS Access file or in multiple MS Access files, depending on size limitations. If multiple files are used, then additional filenames should be consecutively numbered and appended with the "file number of total number of files" (for example, "HydroFRAC[vintage year of PIDM]-MasterTables-[start date of compilation]-1 of 2 .accdb").

- Open a MS Excel file called "HydroFRAC-TemplateWorksheet.xlsx" and save it as "HydroFRAC[vintage year of PIDM]-Worksheet-[start date of compilation].xlsx". Copy the template in appendix 2 into this Excel file. This file will be used to check the counts to assure that data have not been lost as specified throughout this report.

- From here forward, "HydroFRAC-[vintage year of PIDM]-Worksheet-[start date of compilation].xlsx" will be referred to as "fracworksheet.xlsx" file. 
- Create a text file called "README.txt".

- Use this file to record information about the various tables and files.

- List information such as the data source, date of creation, name of person who created the file, methods/ steps used to compile the data, list of field names, and what the data represent including the year(s) of compilation and any other definitions or explanations needed to document the origin, processing steps, methods, and quality.

\section{Step 3: Use Microsoft Access to store data from "converted treatments" database and from the PIDM}

- Import the converted treatments comma separated values (.csv) file from the ConvertedTreatments Java program into MS Access "converted treatments.accdb" as a new table named JAVA_Converted_Treatments.

- Change the primary key for the JAVA_Converted Treatments table to match the primary key of the IHS WELL_TREATMENT table UWI, SOURCE, TRTM OBS_NO, TRTM_TYPE for consistency and record the total record count of JAVA_Converted_Treatments in the "fracworksheet.xlsx" file.

- Export only the TRTM_TYPE of FRAC and REFRAC converted records with codes to MS Access "master tables.accdb" and name the table JAVA_Converted Treatments FRAC_REFRAC.

- Connect MS Access to an Oracle IHS database (IHS Markit, 2019). MS Access could be linked to an Oracle IHS database (IHS Markit, 2019) using an Oracle Database Connectivity (ODBC) driver, however, a user could also connect using OraNet or other drivers depending on what database software is used. Link the WELL and WELL TREATMENT tables from the PIDM into the "master tables.accdb".

- Create a new usgs treatment table in the "master tables.accdb" by merging the IHS WELL= TREATMENT with the converted treatment fluid amount (TRTM_AMOUNT) and proppant amount (AGENT_AMOUNT) from the JAVA Converted Treatments_FRAC_REFRAC table in the "master tables.accdb".

- In the "fracworksheet.xlsx" file, record the number of records listed in the IHS WELL TREATMENT and the usgs treatment tables.
- In the "fracworksheet.xlsx" file, record the number of records by treatment unit (TRTM_UNIT) and the number of records by proppant unit (AGENT_UNIT) (only of the FRAC or REFRAC treatment types) found in the original IHS WELL_TREATMENT table.

- Compare the counts of converted treatment fluid units (TRTM_UNIT) and converted proppant units (AGENT_UNIT). In the "fracworksheet.xlsx" file, explain discrepancies (if any) between original IHS WELL_TREATMENT and usgs treatment tables.

- Differences in counts could arise because not all treatment fluid (TRTM_FLUID_TYPE) units (TRTM_UNIT) or proppant (AGENT_TYPE) units (AGENT_UNIT) are converted. Note the following:

- Treatment fluid units (converted): $G A L, B B L, Q T$, $C F$, and $M C F$;

- Proppant units (converted): $L B$ and TON;

- Treatment fluid units (not converted): $N U L L, L B$, TON, HOLE, SACK, and FT; and

- Proppant units (not converted): NULL and SACK.

- Records are converted if either the treatment amount (TRTM_AMOUNT) or the proppant amount (AGENT_AMOUNT) has a value.

- Note that the counts for converted records from the usgs treatment table will not likely match counts for TRTM_UNIT and AGENT UNIT from the IHS WELL TREATMENT because a record could have a proppant amount and not a treatment fluid amount or vice versa.

\section{Step 4: Create a master treatment table}

- Record the count of FRAC and REFRAC records from the IHS WELL TREATMENT table and the usgs treatment table in the "fracworksheet.xlsx" file.

- It is possible that the count for FRAC and REFRAC records for IHS WELL TREATMENT and usgs treatment tables could be the same but highly unlikely since not all units are converted from WELL_TREATMENT. Furthermore, there are cases where a record can have a proppant amount (AGENT_AMOUNT) but not a treatment amount (TRTM_AMOUNT). It is more likely that the record count for usgs treatment table will be less than the record count for IHS WELL TREATMENT. There should never be more FRA $\bar{A}$ and REFRAC records in the usgs treatment table than in the IHS WELL TREATMENT table because the 
usgs treatment table is created from the IHS WELL TREATMENT table.

- Create a query called Treatments $w$ codes in the "converted treatments.accdb" to link code information from the IHS tables in the PI CODES schema ( $\mathrm{R}$ ADDITIVE TYPE, $\mathrm{R}$ PROPPANT TYPE, $\underline{R}$ TREATMENT_FLUID, and $\mathrm{R}$ _TREATMENT TYPE) to the usgs treatment table to convert the IHS codes to full text. Note that $P I C O D E S$ is a schema that holds all the tables that convert "codes" to their actual value, therefore, the $\underline{P I C O D E S}$ table converts "FRAC" to "Fracturing".

- Make sure the joined IHS PI_CODES tables are specified to retain all converted records and only retain

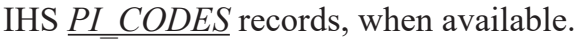

- Include field names: UWI, SOURCE, TRTM OBS_NO, TRTM_TYPE, TRTM_TYPE_NAME, TEST_TYPE, RUN_NO, TEST_NUMBER, TRTM_START_DATE, ADDITIVE_TYPE, ADDITIVE_TYPE_NAME, TRTM_FLUID_TYPE, TRTM_FLUID_TYPE_NAME, TRTM_AMOUNT, TRTM_UNIT, AGENT_TYPE, AGENT_NAME, AGENT_AMOUNT, and AGENT_UNIT.

- In the "fracworksheet.xlsx" file, record the number of records in the Treatments_w_codes query after linking the IHS PI CODES.

- Verify that the number of Treatments_w_codes query records match the number of records in the usgs treatment table. The number of records in the query should be the exact same as the number in the usgs treatment table. This provides the following:

- Verifies that records were not inadvertently removed because they did not have a code;

- Verifies that codes are connected correctly and that the code name has been added (for example, FRAC [TRTM_TYPE] now has an additional column [TRTM_TYPE_NAME] in this case, "Fracturing");

- Checks that if a code is empty (for example, the ADDITIVE_TYPE is empty) then the entire record is not removed when records are joined.

- If the number of records in the Treatments_w_codes query agrees with the number of records in the usgs treatment table, create a new table from the Treatments_w_codes query in the previous step that includes only the FRAC and REFRAC records with codes. Export the new table to the "master tables.accdb" database file calling the new table Master Treatment table, within the "master tables.accdb" file.

- If the record counts do not agree, repeat step 4.
- Check that the Master Treatment table record count matches the FRAC and REFRAC count from the usgs treatment table. Because the query from the previous step was used to create a new table called Master Treatment table within the "master tables.accdb", this step verifies that the Treatments w codes query and Master Treatment table both have the same number of FRAC and REFRAC records. Record counts should match before proceeding to the next step.

- If the record counts do not match, delete the Master Treatment table and repeat step 4.

- Use the Master Treatment table to create a query called Unique UWIs using the "Group by" function to obtain the count of unique wells (UWIs) from the Master Treatment table.

- Record the count of unique wells (UWIs) from the Unique UWIs query to get all the well information for the UWIs in the Master Treatment table. The count is used to verify the number of wells after adding the well information.

- Record explanations and information regarding the Master Treatment table data in the README text file.

\section{Step 5: Create master wells table(s)}

\section{Step 5a: Compile FRAC/REFRAC wells from the PIDM and check}

- Using the Unique UWIs query from the previous step, create a new query called Unique_UWIs_w_codes. Link the unique UWIs from the Unique $\boldsymbol{U} \boldsymbol{W} I \boldsymbol{s}$ query to the IHS WELL table and to the IHS database (IHS Markit, 2019) code tables schema (PI_CODES) to obtain the following well field names:

- From IHS WELL table

- SPUD_DATE, PI_COMP_DATE, COMP_YEAR, PI_SURFACE_LAT as LAT, PI_SURFACE_ LONG as LON; and

- From IHS code tables $(\underline{P I C O D E S})$

- PI_R_FINAL_STATUS.LONG_NAME as FINAL_LSTATUS, R_COUNTY.LONG_NAME as COUNTY, R_PROVINCE_STATE. LONG_NAME as STATE, R_GEOLOGIC_ PROV.LONG_NAME as GEO_PROV, and R_WELL_PROFILE_TYP.LONG_NAME as HOLE_DIR_NAME. 
- When linking codes, keep all original records (UWIs from the Unique $\boldsymbol{U W I}$ query) and add only the IHS PI_CODES table field names that match.

- Note that because of a technical issue with MS Access, the user must change the identifier for PI SURFACE_LAT to LAT and PI_SURFACE_LONG to LON.

- In the "fracworksheet.xlsx" file, record the number of records in the Unique UWIs w codes query after linking the codes. Make sure that the number of unique UWIs in the Unique UWIs w codes query matches the count of unique UWIs from the $\underline{\text { Unique }}$ $\underline{U W I S}$ query.

- If the count of unique UWIs in the Unique UWIs query match the count from the Unique UWIs w codes query, use the Unique UWIS w codes query to create a new query called Master Well Table-All.

- If the counts do not match, make sure the $\underline{\text { Unique }}$ $\underline{\boldsymbol{U W I}} \mathbf{s}$ query is correct following step 4 and repeat step 5a.

\section{Step 5b: Compile FRAC/REFRAC onshore wells and check}

- Using the Master Well Table-All query create a temporary query to obtain the count of wells by State using SQL's (Structured Query Language) "Group By" and "Count" functions.

- “Group By" PROVINCE_STATE and "Count" UWI.

- Since the Master Well Table-All query contains all the unique UWIs that had a FRAC or REFRAC treatment, this step should provide a count of the $\boldsymbol{F R A C}$ or $\boldsymbol{R E F R A C}$ wells by State.

- In the "fracworksheet.xlsx" file, record the count of UWIs by State.

- Create another query called Master Well TableLand [based on the Master_Well Table-All query]. Remove all offshore wells by excluding entries with a PROVINCE_STATE value greater than 50 .

- The process uses IHS PROVINCE_STATE values to determine if a well is offshore or onshore. We assume onshore wells have a PROVINCE_STATE value that is equal to one of the 50 States in the United States and those wells without value or with a value that is not equal to one of the 50 States in the United States are assumed to be located offshore presumably in waters outside of the continental land mass.
- Create another temporary query based on the Master Well Table-All query using the "Group By" and "Count" functions to get the counts by State:

- "Group By" PROVINCE_STATE and "Count" UWI.

- The difference between the count by State from the Master Well Table-All query and the count by State from Master Well Table-Land query is equal to the number of offshore wells.

- In "fracworksheet.xlsx" file, record the total number of wells listed in the Master Well Table-Land query. Check that the number of wells matches the counts from Master Well Table-All query by State (not including the offshore State codes).

- If counts do not match, repeat step 5b.

Step 5c: Compile FRAC/REFRAC onshore wells completed during the years of interest and check

- Using the Master Well Table-Land query, create a temporary query to get the count of wells by State using the "Group By" and "Count" functions.

- "Group By" COMP_YEAR and "Count" UWI.

- Since the Master Well Table-Land query contains all the onshore unique UWIs that had a FRAC or $\boldsymbol{R E F R} \boldsymbol{A C}$ treatment, this step should provide a count

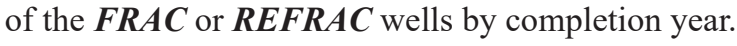

- In the "fracworksheet.xlsx" file, record the count of UWIs by COMP_YEAR listed in the temporary Master_Well Table-Land query.

- From this point on, the user can compile data for various year(s) of interest by repeating each of the following steps for each grouping ("[start year of interest-end year of interest]") of completion year (for example, 2000, or 2000-2010).

- Create query/queries from Master Well Table-Land query to obtain all wells by COMP_YEAR for the year(s) of interest and call the query/queries Master Well Table-Land-/start year of interest-end year of interestl query/queries.

- Record the record count for each Master Well Table-Land-/start year of interest-end year of interestl query in the "fracworksheet.xlsx" file.

- Compare the Master Well Table-Land-/start year of interest-end vear of interestl query counts by COMP_YEAR for each range of year(s) of interest to the counts by COMP_YEAR from the Master Well Table-Land temporary query. Check that the 
record counts by COMP_YEAR match for wells in year(s) of interest.

- If counts do not match, repeat step 5c.

Step 5d: Compile FRAC/REFRAC oil and gas onshore wells completed in the years of interest and check.

- Create a new query/queries for each Master Well Table-Land-/start year of interest-end year of interest] query and only include wells that have a FINAL_STATUS of either OIL WELL or GAS WELL. Name the query/queries as follows: Master Well_Table-Land-OilGas-/start year of interest-end vear of interestl.

- Using the Master Well Table-Land-/start vear of interest-end year of interestl queries for each year(s) of interest, record the counts of the FINAL_STATUS in the "fracworksheet.xlsx" file.

- Check that the count from the Master Well TableLand-/start year of interest-end year of interestl queries of all FINAL_STATUS matches the Master Well-Table-Land-OilGas-/start year of interest-end year of interestl queries for only the FINAL STATUS of type OIL WELL and GAS WELL.

- If counts do not match, repeat step $5 \mathrm{~d}$.

Step 5e: Compile FRAC/REFRAC, horizonal, vertical, directional, oil and gas onshore wells completed for year(s) of interest.

- Within each Master_Well Table-Land-OilGas-/start vear of interest-end vear of interestl query created and checked in the previous step containing FRAC/REFRAC wells, OIL WELL, and GAS

WELL records for each year(s) of interest, count the HOLE_DIRECTION records and record this count in the "fracworksheet.xlsx" file.

- Create a new query/queries based on each Master Well Table-Land-OilGas-/start year of interest-end vear of interestl query called Master Well TableLand-OilGas-DHV-/start year of interest-end year of interestl query and only include wells that have a HOLE_DIRECTION of either HORIZONTAL, DIRECTIONAL, Or VERTICAL.

- Verify that the counts of HOLE_DIRECTION records from each Master Well Table-LandOilGas-DHV-/start year of interest-end year of interestl query match the count of records with a HOLE_DIRECTION of HORIZONTAL, DIRECTIONAL, or VERTICAL in the Master Well Table-Land-OilGas-/start year of interest-end vear of interestl query.

- These counts should match because one is a subset of the other. This is a check to verify that errors were not made when querying only the vertical, directional, and horizontal wells.

- If counts do not match, repeat step 5e.

Step 5f: Create table(s) of FRAC/REFRAC horizontal, directional, oil and gas onshore wells completed in the year(s) of interest.

- For each Master Well Table-Land-OilGas-DHV-lstart vear of interest-end year of interestl query, record the number of records in the "fracworksheet.xlsx" file.

- Use each Master Well Table-Land-OilGas-DHV[start vear of interest-end vear of interest] query/ queries to create a table(s) called Master Well Table[start year of interest-end year of interest].

- After creating each Master Well Table-[start year of interest-end year of interestl table, record the total number of records and check against the record count of the corresponding Master Well TableLand-OilGas-DHV-/start year of interest-end year of interestl query.

- If counts do not match, repeat step $5 f$.

- Update the README text file with information about the various tables and files, such as data source, date of creation, name of the person who created the file, methods/steps used to compile the data, list of field names, and what the data represent including years of interest and any other definitions or explanations needed to document the origin, processing steps, methods, and (or) quality.

\section{Step 6: Create master table(s)}

- Link the well information to the treatment information to create a "Master Table".

- Create a query called Master TableO-/start vear of interest-end vear of interestl based on each Master Well Table-[start year of interest-end year of interestl and link the Master Treatment table to each Master Well Table-[start vear of interest-end year of interestl using the UWI. 
- This step results in a Master Table query that

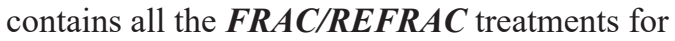
all onshore wells in the U.S. by State completed in the years of interest that have a FINAL STATUS of OIL WELL or GAS WELL and a HOLE DIRECTION OF HORIZONTAL, DIRECTIONAL, or VERTICAL.

- Check that data were not lost in the compilation.

- In the "fracworksheet.xls" file, record the counts of the UWIs listed in the Master Well Table-[start year of interest-end year of interest].

- Using the Master TableO-/start year of interest-end vear of interestl query/queries, create a temporary query for each year(s) of interest. Count the unique UWIs, which should match the number of wells (UWIs) from the Master Well Table-[start year of interest-end year of interest] of the same year(s) of interest.

- If count does not match, repeat step 6.

- If the count of unique wells (UWI) from the Master TableO-/start year of interest-end year of interestl query matches the count of UWIs from Master Well Table-[start year of interest-end year of interest], make a table for each year(s) of interest and call the table(s) Master Table-[start year of interest-end year of interest]. Record the total number of records in each table in the "fracworksheet.xls" file. The record count from Master Table-[start year of interest-end year of interest] should match the corresponding record count from Master TableO-/start year of interest-end year of interest].

- If records counts do not match, repeat step 6.

- Include the field names: UWI, SPUD_DATE, PI_COMP_DATE, COMP_YEAR, STATE, COUNTY, HOLE_DIRECTION, HOLE_DIR_ NAME, GEO_PROVV, FINAL_STATUS, $\bar{L} A T$, LON, SOURCE, TRTM_OBS_NO, TRTM_TYPE, TRTM_TYPE_NAME, TEST_TYPE, RUN_NO, TEST_NUMBER, TRTM_START_DATE, ADDITIVE_TYPE, ADDITIVE_TYPE, NAME, TRTM_FLUID, TRTM_FLUID_NAME, TRTM_ AMOUNT, TRTM_UNIT, AGENT_TYPE, AGENT_TYPE_NĀME, AGENT_ĀMOUNT, and AGENT_UNIT.

- Update the README text file with information about the various tables and files, such as data source, date of creation, name of person who created the file, methods/steps used to compile the data, list of field names, and what the data represent including years of interest and any other definitions or explanations needed to document the origin, processing steps, methods, and (or) quality.

\section{Step 7: Check master table(s) counts}

- Check that no records were lost between the query and table.

- Open each Master Table-[start vear of interestend year of interestl table and go to the last record and record the total number of records in the "fracworksheet.xlsx" file.

- Verify that the count of each Master Table-[start year of interest-end year of interestl matches the count from the corresponding Master TableO[start year of interest-end year of interest] query. If this is not the case, then go back to last known correct check.

- Verify and record in "fracworksheet.xlsx" file that each Master Table-[start year of interest-end year of interestl table only contains treatments of TRTM_TYPE FRAC or REFRAC, that the FINAL_STATUS only has OIL WELL or GAS WELL, the COMP_YEAR only includes the years of interest, and the HOLE_DIRECTION contains only HORIZONTAL, DIRECTIONAL, or VERTICAL and onshore wells by State.

- If the record counts do not match, repeat steps 4 to 7 .

\section{Step 8: Start the process to compile treatment totals}

- For each Master table-[start year of interest-end year of interestl, create a temporary query that counts the treatment fluid amount units (TRTM_AMT_ UNIT). Verify that there is only unit of $\bar{C} \boldsymbol{M}$ (cubic meters). Record the counts of records in the "fracworksheet.xlsx" file.

- As mentioned in step 3, if there are TRTM_AMT_ UNIT other than $\boldsymbol{C U M}$, then a mistake has been made in the first step. The user must start the process from step 1 because the treatment units were not converted properly.

- Some TRTM_AMT_UNIT entries could be blank in cases where the record had a proppant amount but not a treatment amount.

- For each Master Table-[start year of interest-end year of interest], create a query called Treatments $w$ values-[start year of interest-end year of interestl] that 
retains only the records that have a treatment amount (TRTM_AMT). Record the counts in the "fracworksheet.xlsx" file.

- Check that the count of treatments with a treatment amount (TRTM_AMT) in each query matches the count of the treatment units TRTM_AMT_UNITs (in this case, this is equal to the count of $\boldsymbol{C} \boldsymbol{U} \boldsymbol{M}$ entries).

- If the counts match, use each Treatments w values[start vear of interest-end vear of interest] query to make a new table called Master Table w TRTM AMT-[start year of interest-end year of interest].

- Include field names: UWI, SPUD_DATE, PI_COMP_DATE, COMP_YEAR, STATE, COUNTY, HOLE_DIRECTION, HOLE_DIR_ NAME, GEO_PROV, FINAL_STATUS, LAT, LON, SOURCE, TRTM_OBS_NO, TRTM_TYPE, TRTM_TYPE_NAME, TEST_TYPE, RUN_NO, TEST_NUMBER, TRTM_START_DATE, ADDITIVE_TYPE, ADDITIVE_TYPE_NAME, TRTM_FLUID_TYPE, TRTM_FLUID_TYPE_ NAME, TRTM_AMOUNT, TRTM_UNIT, AGENT_TYPE, AGENT_TYPE_NAME, AGENT AMOUNT, and AGENT_UNIT.

- If counts do not match, then repeat step 8 .

- Record the number of records of each Master Table w TRTM AMT-[start year interest-end year interest] table in the "fracworksheet.xlsx" file.

- Update the README file with information on data source, date of creation, name of person who created the file, methods/steps used to compile the data, definition of columns and rows, and what the data represent including years of compilation and any other definitions or explanations needed to document the origin, processing steps, methods, and (or) any other notes that would reflect quality.

\section{Step 9: Create master well treatment totals table(s)}

- Create a new query called Unique wells w TRTM AMT-[start year of interest-end year of interest] based on the Master Table w TRTM AMT-[start year of interest-end year of interestl table. Apply the "Group By" function to the UWI to return a list of all unique wells. Record the total for each year(s) of interest table in "fracworksheet.xlsx" file.

- Create a query/queries called $\underline{\text {-Master Wells }}$ Treatment Totals-/start vear of interest-end vear of interestl for each Master Table w TRTM AMT[start year of interest-end year of interest].
- Include the well information (UWI, SPUD YEAR, PI_COMP_DATE, COMP_YEAR, FINAL_STATUS, HOLE_DIRECTION, HOLE_ DIR_NAME, STATE, COUNTY, GEO_PROV, LAT and LON).

- Include only the TRTM_AMT (treatment amount) and TRTM_UNIT (treatment unit) from the treatment information contained in the Master Table w TRTM AMT-[start year of interest-end year of interestl.

- Use the "Group By" function within the query, group by well information such that a single record is retrieved for every well. Use the "Sum" function to calculate the sum of the treatment amounts (TRTM AMTs) resulting in a single treatment amount per well.

- If the name of the column heading is not changed, the resulting query will name the column heading "SumOfTRTM_AMOUNT". This might cause confusion because the next query also generates a "SumOfTRTM_AMOUNT" if the name is not changed as well.

- It is recommended that the column be renamed “TOTAL_TRTM_AMOUNT".

Record the record count in the "fracworksheet.xlsx" file.

- If the counts from the query/queries $\underline{Q}$-Master Wells Treatment Totals-/start vear of interest-end vear of interestl match the totals from the Unique Wells w TRTM AMT-/start year of interest-end year of interestl query, then using query $\underline{Q}$-Master Well Treatment Totals-/start vear of interest-end year of interest] create a new table called Master Well Treatment Totals-[start year of interest-end year of interestl for each year(s) of interest and record the record count in the "fracworksheet.xlsx" file.

- If the record counts do not match, then repeat step 9.

- Update the README text file to document the data source, date of creation, name of person who created the file, methods/steps used to compile the data, list of field names, and what the data represent including years of compilation and any other definitions or explanations needed to document the origin, processing steps, methods, and factors that could affect the data quality.

\section{Step 10: Create a master well treatment total by fluid table(s)}

- Create a new query (or queries) called $\underline{Q}$-Well Treatment Totals by Fluid-/start year of interest-end year of 
interestl based on the Master Table w TRTM AMT[start year of interest-end year of interest] table.

- Include the well information (UWI, SPUD YEAR, PI_COMP_DATE, COMP_YEAR, FINAL_STATUS, HOLE_DIRECTION, HOLE DIR_NAME, STATE, COUNTY, GEO_PROV, LAT and LON).

- Include the treatment information (TRTM_FLUID_ TYPE, TRTM_FLUID_TYPE_NAME, and TRTM_AMT).

- In the O-Well Treatment Totals by Fluid-/start year of interest-end year of interestl query, compute the total volume of each fluid type injected into each well by applying the "Group By" function to all well information, TRTM_FLUID_TYPE, and TRTM_FLUID_ TYPE_NAME, and apply the "Sum" function to the TRTM_AMT.

- If the name of the column heading is not changed, the resulting query will name the column heading "SumOfTRTM_AMOUNT". This might cause confusion because the previous query also generated a "SumOfTRTM_AMOUNT" if the name was not changed.

- It is recommended that this column be renamed “TOTAL_TRTM_FLUID_AMOUNT".

- Create a new query/queries called Unique Wells O-Well Treatment Totals by Fluid-/start vear of interest-end year of interestl based on the $\underline{Q}$-Well Treatment Totals by Fluid-/start vear of interest-end vear of interestl query and use the "Group By" function for only the UWI.

- Record the counts for each $\underline{O-W e l l}$ Treatment Totals by Fluid-[start year of interest-end year of interest] and Unique Wells $\mathbf{Q}$-Well Treatment Totals by Fluid-/start year of interest-end year of interestl and check that the Unique Well Q-Well Treatment Totals by Fluid-/start year of interest-end year of interest] count matches the Unique Wells w TRTM AMT-Istart vear of interestend year of interestl count from step 9.

- If counts do not match, repeat step 10.

- If counts match, create a new table(s) called Master Well Treatment Totals by Fluid-[start year of interest-end year of interestl for each year(s) of interest.

- Verify that the counts of records in the $\underline{\boldsymbol{O} \text {-Well }}$ Treatment Totals by Fluid-/start vear of interest-end vear of interest] query match the counts of records in the Master Well Treatment Total by Fluid-[start year of interest-end year of interest] table.
- If the counts do not match, then repeat step 10.

\section{Step 11: Remove proprietary data}

The proprietary information should be removed prior to public release of the data, in accordance with IHS Markit (IHS Markit, 2019) agreements.

- Remove all proprietary information considered proprietary by IHS Markit (IHS Markit, 2019) from all the MS databases (.accdb) and tables as well as from any text files created using this report. For example, proprietary information includes, but is not limited to the following: well identity information such as the UWI (or API), latitude (LAT), and longitude (LON) of the wells.

- Note that this step only applies to the tables created by the user using this method. The original IHS tables are static and should retain the well identity information.

- Final data products derived from this method should be reviewed by IHS Markit prior to release in accordance with IHS Markit agreements (IHS Markit, 2019).

\section{Summary}

Completion of this procedure will result in the following MS Access files and tables within MS Access files:

- "HydroFRAC-[vintage year of PIDM]ConvertedTreatments-[start date of compilation]. accdb";

- "HydroFRAC-[vintage year of PIDM]MasterTables-[start date of compilation].accdb";

- Master Treatment Table;

- Master Well Table-[start vear of interest-end vear of interestl for all year groupings;

- Master Table-[start year of interest-end year of interestl for all year groupings;

- Master Table w TRTM AMT-[start year of interestend year of interestl for all year groupings;

- Master Well Treatment Totals-[start year of interestend vear of interestl for all year groupings; and

- Master Well Treatment Total by Fluid-[start year of interest-end year of interestl for all year groupings.

A description of each of these tables is found in appendix 3. These data provide information about the treatment fluids, treatment fluid types, and treatment fluid amounts injected into wells for hydraulic fracturing. Data are organized by general well location (State, county, and geologic 
province), by well orientation (horizontal, vertical, and directional), and well type (oil or gas). Data tables can be exported to MS Excel for further analysis.

\section{Acknowledgments}

Data compiled herein were derived from the IHS Markit, 2019, U.S. Well History and Production Relational Database (IHS Markit, 2019). Funding for this research was provided by the U.S. Geological Survey Energy Resources Program. The authors wish to thank the reviewers whose comments greatly improved the manuscript.

\section{References Cited}

Coleman, J.L., 2009, Tight-gas sandstone reservoirs - The 200-year path from unconventional to conventional gas resource and beyond, in Carr, T., D’Agostino, T., Ambrose, W., Pashin, J., and Rosen, N.C., eds., Unconventional energy resources-Making the unconventional conventional: 29th Annual GCSSEPM Foundation Bob F. Perkins Research Conference, Houston, Tex., December 6-8, 2009, Proceedings Gulf Coast Section-Society of Economic Paleontologists and Mineralogists, GCS029, p. 397-441.

Economides, M.J., and Nolte, K.G., 2000, Reservoir stimulation (3d ed.): West Sussex, England, John Wiley \& Sons, $807 \mathrm{p}$.

Elbel, J., and Britt, L., 2000, Fracture treatment design, chap. 10 in Economides, M.J., and Nolte, K.G., eds., Reservoir stimulation (3d ed.): West Sussex, England, John Wiley \& Sons, p. 10-1 to 10-50.

Ground Water Protection Council and ALL Consulting, 2009, Modern shale gas development in the United States-A primer: U.S. Department of Energy, Office of Fossil Energy and National Energy Technology Laboratory, 98 p. [Also available at https://www.energy.gov/fe/downloads/modernshale-gas-development-united-states-primer.]

Gulbis, J., and Hodge, R.M., 2000, Fracturing fluid chemistry and proppants, chap. 7 in Economides, M.J., and Nolte, K.G., eds., Reservoir stimulation (3d ed.): West Sussex, England, John Wiley \& Sons, p. 7-1 to 7-23.

Holditch, S.A., 2007, Hydraulic fracturing, chap. 8 in Clegg, J.D., ed., Petroleum engineering handbook, volume IVProduction operations engineering: Society of Petroleum Engineers, p. 323-366.
IHS Markit, 2019, U.S. well history and production relational database: Englewood, Colo., IHS Markit web page, accessed January 15, 2020, at https://ihsmarkit.com/ products/us-well-data.html.

Montgomery, C.T., and Smith, M.B., 2010, Hydraulic fracturing-History of an enduring technology: Journal of Petroleum Technology, v. 62, no. 12, p. 26-40. [Also available at https://doi.org/10.2118/1210-0026-JPT.]

U.S. Environmental Protection Agency, 2004, Evaluation of impacts to underground sources of drinking water by hydraulic fracturing of coalbed methane reservoirs: U.S. Environmental Protection Agency, Office of Water, Office of Ground Water and Drinking Water, EPA 816-R-04003, variously paged.

Veatch, R.W., Jr., 1983a, Overview of current hydraulic fracturing design and treatment technology-Part 1: Journal of Petroleum Technology, v. 35, no. 4, p. 677-687. [Also available at https://doi.org/10.2118/10039-PA.]

Veatch, R.W., Jr., 1983b, Overview of current hydraulic fracturing design and treatment technology_Part 2: Journal of Petroleum Technology, v. 35, no. 5, p. 853-864. [Also available at https://doi.org/10.2118/11922-PA.] 



\section{Appendixes}

Appendix 1. Java program, "ConvertTreatments"

Appendix 2. IHS Units Conversion Factors

Appendix 3. List of Tables Compiled

Appendix 4. The "fracworksheet.xlsx" File 


\section{Appendix 1. Java program, "ConvertTreatments"}

import java.io.*;

import java.sql.*;

import java.util.Properties;

/**

* ConvertTreatments_only_IHS_conv is meant to make a connection to our internal IHS oracle server

*and go through the WELL_TREATMENT table for various treatment fluid units and proppant (agent)

*units and convert to a common

* unit only using the conversions found in the IHS PI_ADMIN.PPDM_UNIT_CONVERSION table. This

* program writes info to a comma separated values (csv) file but only writes the records that had either a

*treatment fluid amount or

* an agent (proppant) amount.

*

* @author (Brian A Varela)

* @version (11/14/2008)

*/

public class ConvertTreatments_only_IHS_conv

\{

/**

* Constructor for objects of class ConvertTreatments

*/

public ConvertTreatments_only_IHS_conv()

\{

\}

\section{/**}

* Most of the work is done in the main method. The main method sets up the connection to the *oracle database and gets the user input of which unit to convert to; either cubic meters or gallons for *the treatment fluid type

* and pounds for the proppant amount. The main method also creates the output files and reads in *the input file. The only thing not done by the main method is the conversion

$*$

* @ param type String used to hold the unit to be converted to; either CUM for cubic meters or GAL *for gallons

* @param amount double used to hold the treatment fluid amount

* @param agent_amt double used to hold the proppant amount

*/

public static void main(String args[])

\{

String type="';

double amount=-1.0d, agent_amt=-1.0d;

try\{

System.out.printIn("Program Starting...");

//create connection to oracle

String url = "jdbc:oracle:oci:@”

+"(DESCRIPTION=(ADDRESS=(PROTOCOL=TCP) $($ HOST=igskaecgas020.cr.usgs.gov) $($ PORT=1521))" 


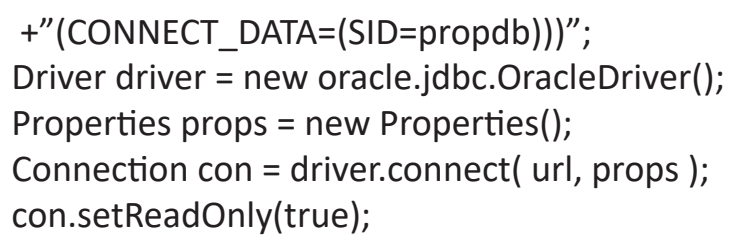

PrintWriter out $=$ new PrintWriter(new FileWriter("Converted_WELL_TREATMENTS-"+ type.toUpperCase()+".csv"));

out.printIn(“UWI,SOURCE,TRTM_OBS_NO,TRTM_TYPE,TEST_TYPE,RUN_NO,TEST_NUMBER,"+ "TRTM_START_DATE,ADDITIVE_TYPE,TRTM_FLUID_TYPE,TRTM_AMOUNT,TRTM_UNIT,AGENT_TYPE,"+ “AGENT_AMOUNT,AGENT_UNIT,ORIGINAL_TRTM_UNIT,ORIGINAL_AGENT_UNIT");

PreparedStatement pstmt = con. prepareStatement (

"SELECT UWI, SOURCE, TRTM_OBS_NO, TRTM_TYPE, TEST_TYPE, RUN_NO,"+

"TEST_NUMBER, TRTM_START_DATE, ADDITIVE_TYPE, TRTM_FLUID_TYPE,"

"TRTM_AMOUNT, TRTM_UNIT, AGENT_TYPE, AGENT_AMOUNT, AGENT_UNIT "+ "FROM PIDM.WELL_TREATMENT"+

"WHERE TRTM_AMOUNT Is Not Null OR AGENT_AMOUNT is Not Null”);

ResultSet trtm = pstmt.executeQuery();

//loop through all treatments and figure out which have values and print out other information //like UWI, SOURCE, TRTM_OBS_NO, etc.

while(trtm.next())

\{ //amount

if(trtm.getString(11) != null) //if treatment amount is not null convert and store in variable

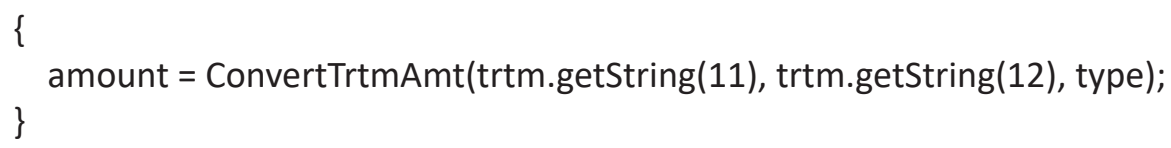

if(trtm.getString(14) != null) //if proppant amount is not null convert and store in variable //agent_amt

if(amount != -1.0d || agent_amt != -1.0d) //if treatment amount or proppant amount is not //null print record out and converted amount

\{ for(int $\mathrm{i}=1 ; \mathrm{i}<11 ; \mathrm{i}++)$ 
\{

if(i==1)

\{ out.print(trtm.getString(i));

\}

else if(i== 8)

\{

if(trtm.getString(i) == null)

\{

out.print(“,');

\}

else

\{ out.print(","+(trtm.getDate(i).getMonth()+1)+" /"+trtm.getDate(i).getDate()+" /"+(trtm. getDate(i).getYear()+1900));

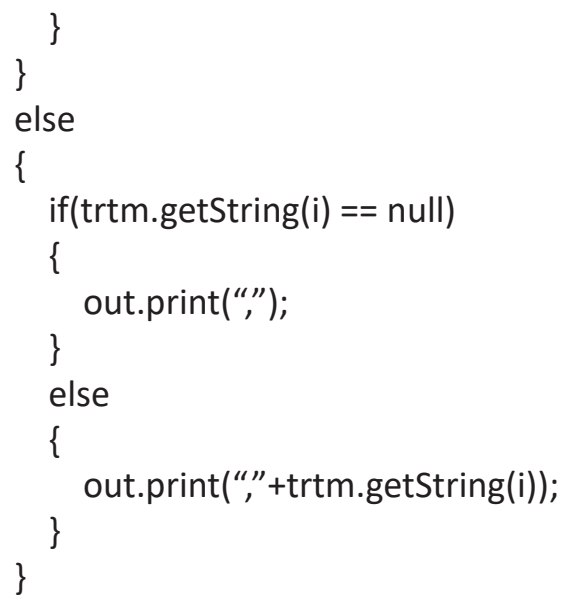

if(amount != -1.0d \&\& agent_amt != -1.0d) //if treatment amount and proppant amount is $/ /$ not null print record out and converted amount - legacy

\{ out.print(“,"+amount+","+type); 


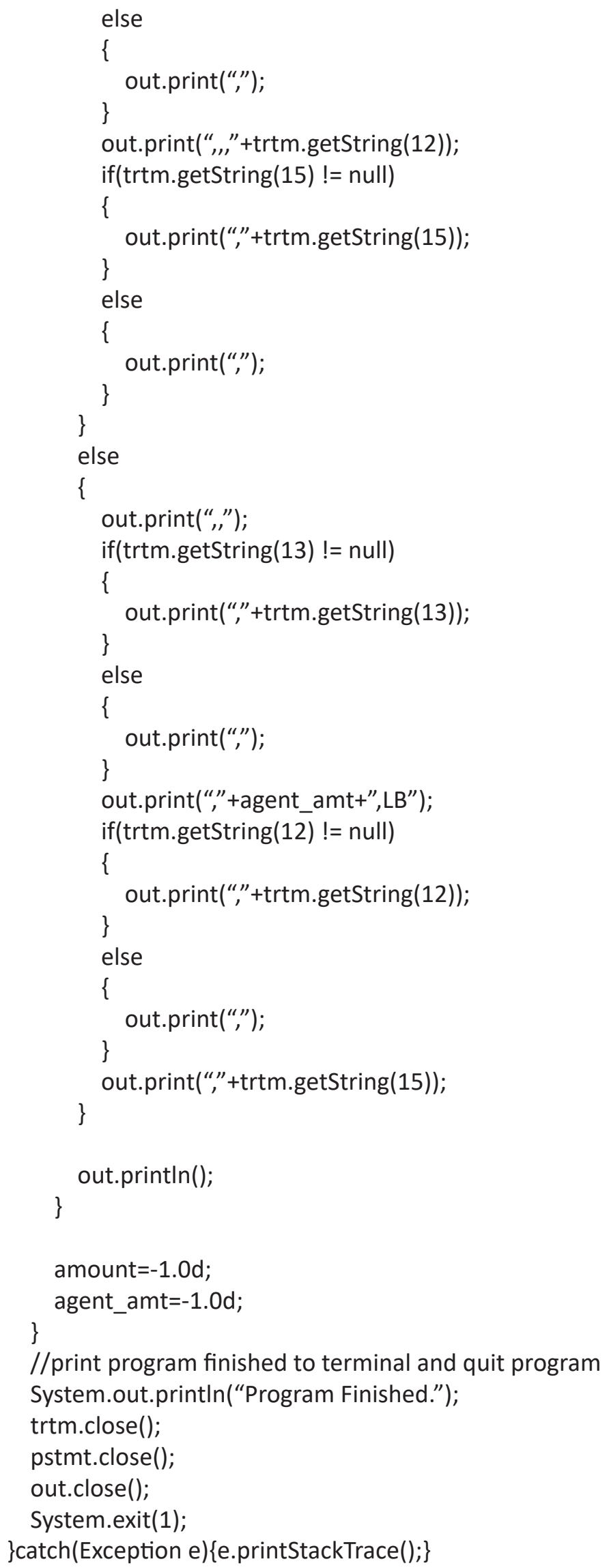




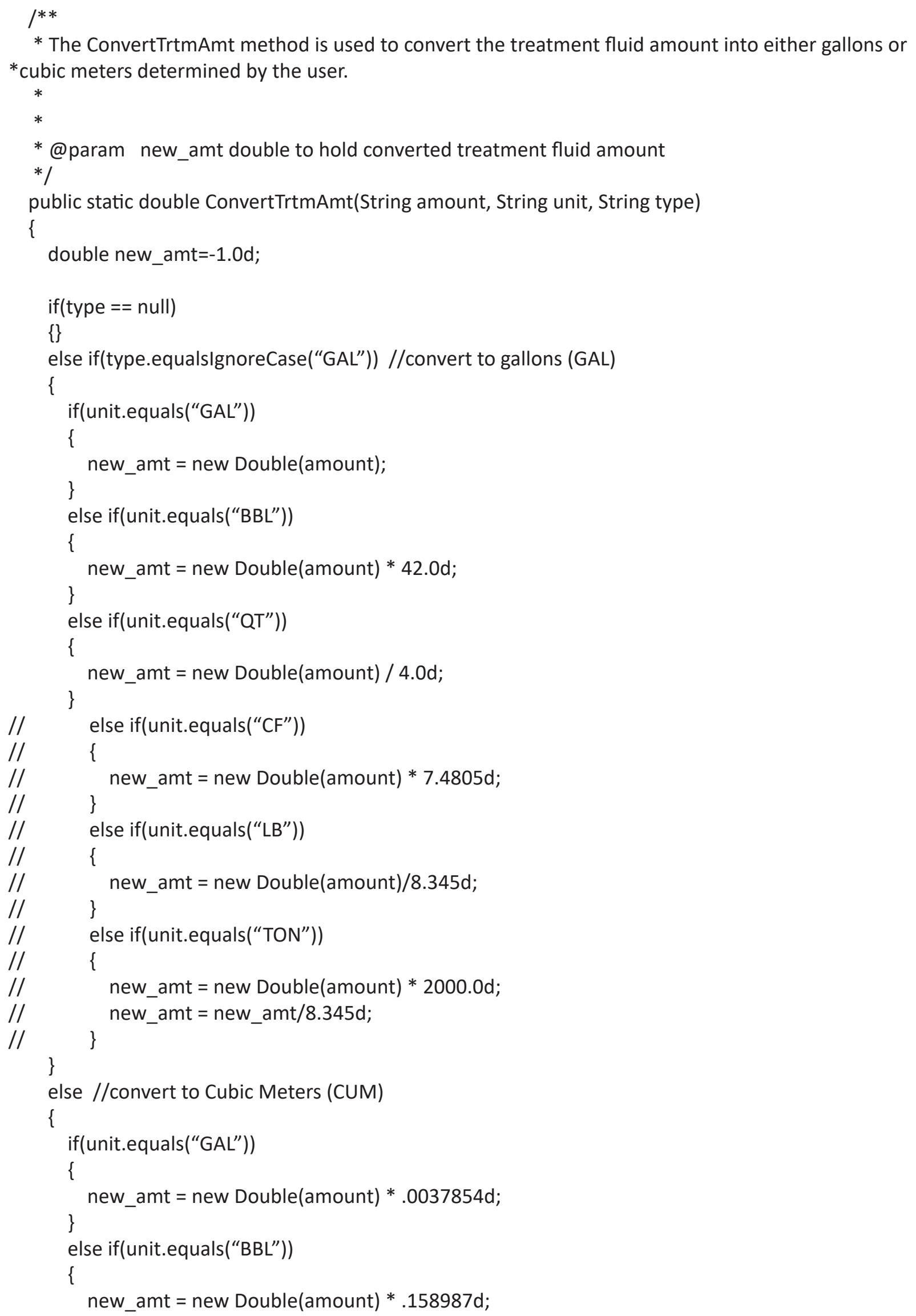




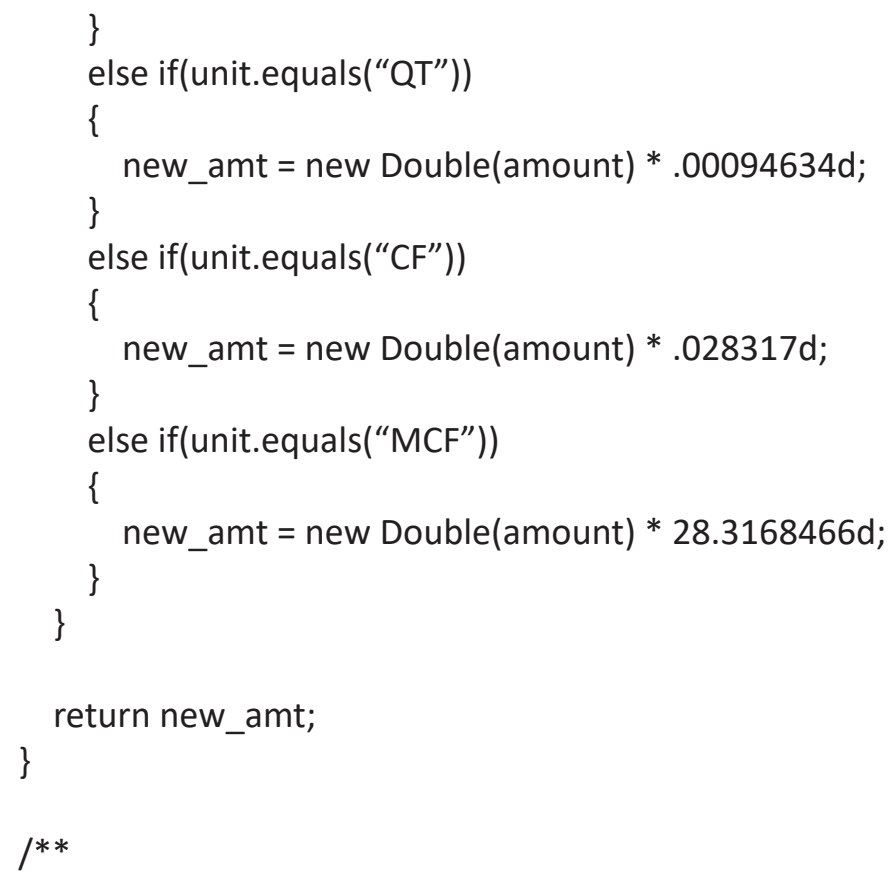

* The ConvertAgentAmt method is used to convert the agent (proppant) amount into pounds (LB). This method takes a String of the amount, a String of the original unit, and a String type that indicates the unit to convert to

$*$ in this case we only convert to pounds (LB).

*

$*$

* @param agent_amt double used to hold the proppant amount */

public static double ConvertAgentAmt(String amount, String unit, String type) \{ 


\section{Appendix 2. IHS Units Conversion Factors}

Table 2.1. IHS Markit (IHS Markit, 2019) unit conversion factors.

[Abbreviations: BBL, barrel; CF, cubic feet; CUM, cubic meters; GAL, gallon; LBS, pounds; MCF, thousand cubic feet; QT, quart]

\begin{tabular}{lll}
\hline \multicolumn{1}{c}{ From unit } & \multicolumn{1}{c}{ To unit } & \multicolumn{1}{c}{ Conversion } \\
\hline \multicolumn{3}{c}{ Treatment fluid } \\
GAL & CUM & GAL $\times 0.0037854$ \\
BBL & CUM & BBL $\times 0.158987$ \\
QT & CUM & QT $\times 0.0009464$ \\
$\mathrm{CF}$ & $\mathrm{CUM}$ & $\mathrm{CF} \times 0.028317$ \\
$\mathrm{MCF}$ & $\mathrm{CUM}$ & $\mathrm{MCF} \times 28.3168466$ \\
\hline \multicolumn{3}{c}{ Agent (proppant) } \\
\hline TON & LBS & $\mathrm{TON} \times 2000$ \\
\hline
\end{tabular}




\section{Appendix 3. List of Tables Compiled}

\section{Master Treatment Table}

- Methods/steps used to compile data: Steps 1,2 and 3.

- Field names: SOURCE, TRTM_OBS_NO, TRTM_TYPE, TRTM_TYPE_NAME, TEST_TYPE, RUN_NO, TEST_NUMBER, TRTM START DATE, ADDITIVE TYPE, ADDITIVE_TYPE_NAME, TRTM_FLUID_TYPE, TRTM_FLUID_TYPE_NAME, TRTM_AMOUNT, TRTM_UNIT, AGENT_TYPE, AGENT_NAME, AGENT_AMOUNT, and AGENT_UNIT.

- Data represented: All hydraulic fracturing or refracturing treatments (coded as FRAC or REFRAC) listed in the PIDM with proppant (AGENT) amounts converted to pounds and treatment fluid amounts converted to cubic meters (CUM).

\section{Master Well Table-[start year of interest-end year of interest]}

- Method/step used to compile data: Step 5.

- Field names: SPUD_DATE, PI_COMP DATE, COMP_YEAR, STATE, COUNTY, HOLE_DIRECTION, HOLE_DRECTION_NAME, GEO_PROV, and FINAL_STATUS.

- Data represented: Data represents all horizontal, directional, or vertical oil and gas wells that were hydraulically fractured or refractured and completed during the years of interest.

\section{Master Table-[start year of interest-end year of interest]}

- Methods/steps used to compile data: Steps 6 and 7.

- Field names: SPUD_DATE, PI_COMP_ DATE, COMP_YEAR, STATE, COUNTY, HOLE_DIRECTION, HOLE_DIRECTION_ NAME, GEO_PROV, FINAL_STATUS, SOÜRCE, TRTM_OBS_NO,TRTM_TYPE, TRTM_TYPE_ NAME, TEST_TYPE, RUN_NO, TEST_NUMBER, TRTM_START_DATE, ADDITIVE_TYPE, ADDITIVE_TYPE_NAME, TRTM_FLUID_TYPE, TRTM_FLUID_TYPE_NAME, TRTM_AMOUNT,
TRTM_UNIT, AGENT_TYPE, AGENT_TYPE_ NAME, AGENT_AMOUNT, and AGENT_UNIT.

- Data represented: All hydraulic fracturing or refracturing treatments applied to directional, horizontal, and vertical oil and gas wells completed during the year(s) of interest and associated with a State code. Each row represents a single treatment such that one well could have multiple treatments (more than one row per well).

\section{Master Table w TRTM_AMT-[start year of interest-end year of interest]}

- Methods/steps used to compile data: Steps 8 and 9.

- Field names: SPUD_DATE, PI_COMP_ DATE, COMP_YEAR, STATE, COUNTTY, HOLE_DIRECTION, HOLE_DIRECTION NAME, GEO_PROV, FINAL_STATUS, SOURCE, TRTM_OBS_NO,TRTM_TYPE, TRTM_TYPE NAME, TEST_TYPE, RUN_NO, TEST_NUMBER, TRTM_START_DATE,ADDITIVE_TYPE, ADDITIVE_TYPE_NAME, TRTM_FLUID_TYPE, TRTM_FLUID_TYPE_NAME, TRTM_AMOUNT, TRTM_UNIT, AGENT_TYPE, AGENT_TYPE_ NAME, AGENT_AMOUNT, and AGENT_UNIT.

- Data represented: Same as Master Table except this table contains only the records that report a treatment amount for a given treatment type. Each row represents a single treatment and associated treatment amount such that one well could have multiple treatments (more than one row per well).

\section{Master Well Treatment Totals-[start year of interest-end year of interest]}

- Methods/steps used to compile data: Steps 8 and 9.

- Field names: SPUD_DATE, PI_COMP_DATE, COMP_YEAR, STATE, COUNTY, HOLE DIRECTION, HOLE_DIRECTION_NAME, GEO_PROV, FINAL_STATUS, TOTAL_TRTM_ AMOUNT, and TRTM_UNIT.

- Data represented: Same as Master Table w TRTM AMT except these records contain only a single sum of all treatment amounts applied to a given well, regardless of treatment fluid type. Each row represents a 
22 Method for Compiling Temporally and Spatially Aggregated Data on Hydraulic Fracturing — Treatments and Wells

single total treatment amount such that one well could only have one entry (one row per well).

\section{Master Well Treatment Total by Fluid-[start year of interest-end year of interest]}

- Data source: IHS PIDM (internal Oracle database) (IHS Markit, 2019).

- Methods/steps used to compile data: Steps 8 and 10.
- Field names: SPUD_DATE, PI_COMP_DATE, COMP_YEAR, STÄTE, COUNTY, HOLEE DIRECTION, HOLE_DIRECTION_NAME, GEO_PROV, FINAL_STATUS, TRTM_FLUID_ TYPE, TRTM_FLUID_TYPE_NAME, TOTAL_ TRTM_FLUID_AMOUNT, and TRTM_UNIT.

- Data represented: Same as Master Table w TRTM AMT except each record represents the sum of all the treatment amounts of a given treatment type applied to a given well such that one well could have multiple entries (more than one row per well). 


\section{Appendix 4. The "fracworksheet.xlsx" File}

The following series of tables are used to document the record counts at various steps throughout the data compilation process.

Table 4.1. Step 3 count of treatment records.

\begin{tabular}{|l|l|}
\hline \multicolumn{2}{|c|}{ Step 3 } \\
\hline
\end{tabular}

Table 4.2. Step 3 count of TRTM_UNIT records.

\begin{tabular}{|l|l|l|l|}
\hline \multicolumn{2}{|c|}{ IHS Table - Count of TRTM_UNIT records } & \multicolumn{1}{|c|}{ Converted Treatment Units } \\
\hline GAL & CountOfUWI & \multicolumn{1}{|c|}{ Count } \\
\hline BBL & & Converted (GAL, BBL, QT, CF, MCF) & \\
\hline QT & & Not Converted (NULL, LB, TON, HOLE, SACK, FT) & \\
\hline CF & Total & \\
\hline MCF & & \\
\hline LB & & Converted Proppant Units & \\
\hline TON & Converted (LB, TON) & \\
\hline HOLE & Not Converted (NULL, SACK) & \\
\hline SACK & Total & \\
\hline FT & & \\
\hline Total & & & \\
\hline
\end{tabular}


Table 4.3. Step 3 count of AGENT_UNIT records.

\begin{tabular}{|l|c|}
\hline \multicolumn{2}{|c|}{ IHS Table - Count of AGENT_UNIT records } \\
\hline AGENT_UNIT & CountOfUWI \\
\hline LB & \\
\hline SACK & \\
\hline TON & \\
\hline Total & \\
\hline
\end{tabular}

Table 4.4. Step 4 FRAC and REFRAC treatment record counts.

\begin{tabular}{|l|l|}
\hline \multicolumn{2}{|c|}{ Step 4 } \\
\hline Record Count of IHS - WELL TREATMENT (FRAC or REFRAC): & \\
\hline Record Count of Converted Treatments - USGS TREATMENT (FRAC or REFRAC) $:$ & \\
\hline Difference & \\
\hline Record Count of Converted Treatments - Treatments_w_codes (FRAC or REFRAC) after linking codes: & \\
\hline Record Count of Master Treatment Table (FRAC or REFRAC): & \\
\hline $\begin{array}{l}\text { Record Count of Unique UWls from Master Treatment Table (FRAC or REFRAC): } \\
\text { * Converted Treatments records contain records with a missing or NULL treatment fluid amount or a } \\
\text { records along with the fact that the Converted Treatment table only contains the FRAC and REFRAC treatment records } \\
\text { there will be an incalculable difference in record counts between the IHS WELL TREATMENT table and the Converted } \\
\text { Treatments table. }\end{array}$ & \\
\hline
\end{tabular}

Table 4.5. Step 5a unique UWI and Master Well Table-All record counts.

\begin{tabular}{|l|l|}
\hline \multicolumn{2}{|c|}{ Step 5a } \\
\hline Record Count of Unique_UWls_w_codes count from Master Treatment Table (FRAC or REFRAC): & \\
\hline Record Count of Master Well Table-All record Count: & \\
\hline
\end{tabular}


Table 4.6. Steps 5b, 5c, 5d, and 5 e count by completion year.

\begin{tabular}{|c|c|}
\hline \multicolumn{2}{|r|}{ Steps $5 b, 5 c, 5 d, 5 e$} \\
\hline COMP_YEAR* & CountOfUWI \\
\hline \multicolumn{2}{|l|}{ start year of interest... } \\
\hline \multicolumn{2}{|l|}{$\ldots 1889$} \\
\hline \multicolumn{2}{|l|}{1895} \\
\hline \multicolumn{2}{|l|}{1896} \\
\hline \multicolumn{2}{|l|}{1897} \\
\hline \multicolumn{2}{|l|}{2012} \\
\hline \multicolumn{2}{|l|}{2013} \\
\hline \multicolumn{2}{|l|}{2014} \\
\hline \multicolumn{2}{|l|}{2015} \\
\hline \multicolumn{2}{|l|}{$2016 \ldots$} \\
\hline \multicolumn{2}{|l|}{ end year of interest } \\
\hline
\end{tabular}


26 Method for Compiling Temporally and Spatially Aggregated Data on Hydraulic Fracturing — Treatments and Wells

Table 4.7. Steps $5 b, 5 c, 5 d$, and $5 e$ count by State.

\begin{tabular}{|c|c|c|}
\hline \multicolumn{3}{|c|}{ Steps $5 b, 5 c, 5 d, 5 e$} \\
\hline \multicolumn{3}{|c|}{ Count by State - Master_Well_Table-Land } \\
\hline & STATE & CountOfUWI \\
\hline \multicolumn{3}{|l|}{ ALABAMA } \\
\hline \multicolumn{3}{|l|}{ ARIZONA } \\
\hline \multicolumn{3}{|l|}{ ARKANSAS } \\
\hline \multicolumn{3}{|l|}{ CALIFORNIA } \\
\hline \multicolumn{3}{|l|}{ COLORADO } \\
\hline \multicolumn{3}{|l|}{ FLORIDA } \\
\hline \multicolumn{3}{|l|}{ GEORGIA } \\
\hline \multicolumn{3}{|l|}{ IDAHO } \\
\hline \multicolumn{3}{|l|}{ ILLINOIS } \\
\hline \multicolumn{3}{|l|}{ INDIANA } \\
\hline \multicolumn{3}{|l|}{ IOWA } \\
\hline \multicolumn{3}{|l|}{ KANSAS } \\
\hline \multicolumn{3}{|l|}{ KENTUCKY } \\
\hline \multicolumn{3}{|l|}{ LOUISIANA } \\
\hline \multicolumn{3}{|l|}{ MARYLAND } \\
\hline \multicolumn{3}{|l|}{ MICHIGAN } \\
\hline \multicolumn{3}{|l|}{ MISSISSIPPI } \\
\hline \multicolumn{3}{|l|}{ MISSOURI } \\
\hline \multicolumn{3}{|l|}{ MONTANA } \\
\hline \multicolumn{3}{|l|}{ NEBRASKA } \\
\hline \multicolumn{3}{|l|}{ NEVADA } \\
\hline \multicolumn{3}{|l|}{ NEW MEXICO } \\
\hline \multicolumn{3}{|l|}{ NEW YORK } \\
\hline \multicolumn{3}{|l|}{ NORTH CAROLINA } \\
\hline \multicolumn{3}{|l|}{ NORTH DAKOTA } \\
\hline \multicolumn{3}{|l|}{$\mathrm{OHIO}$} \\
\hline \multicolumn{3}{|l|}{ OKLAHOMA } \\
\hline \multicolumn{3}{|l|}{ PENNSYLVANIA } \\
\hline \multicolumn{3}{|l|}{ SOUTH DAKOTA } \\
\hline TENNESSEE & & \\
\hline
\end{tabular}




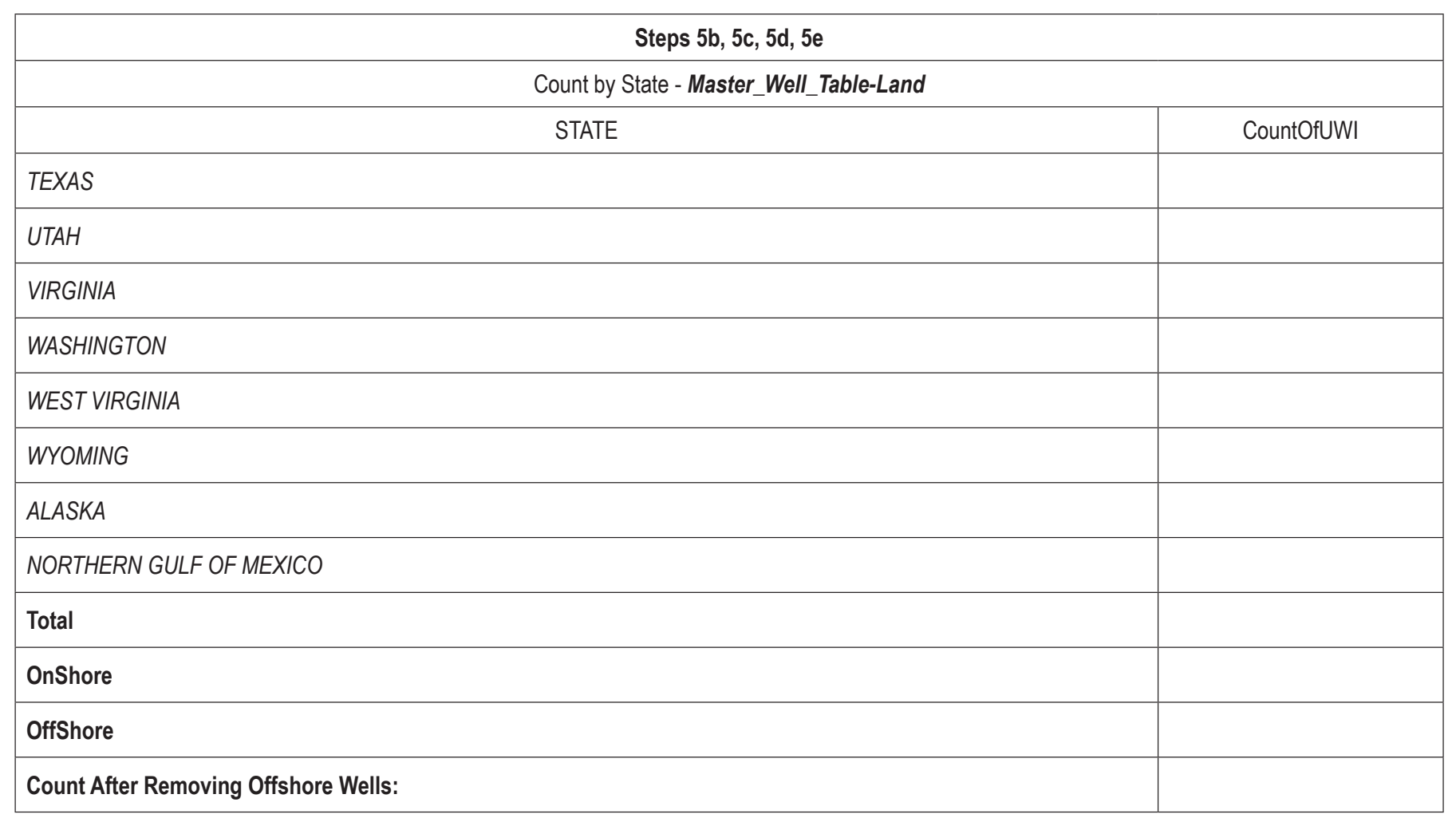

Table 4.8. Steps 5b, 5c, 5d, and 5 e count by Final Status.

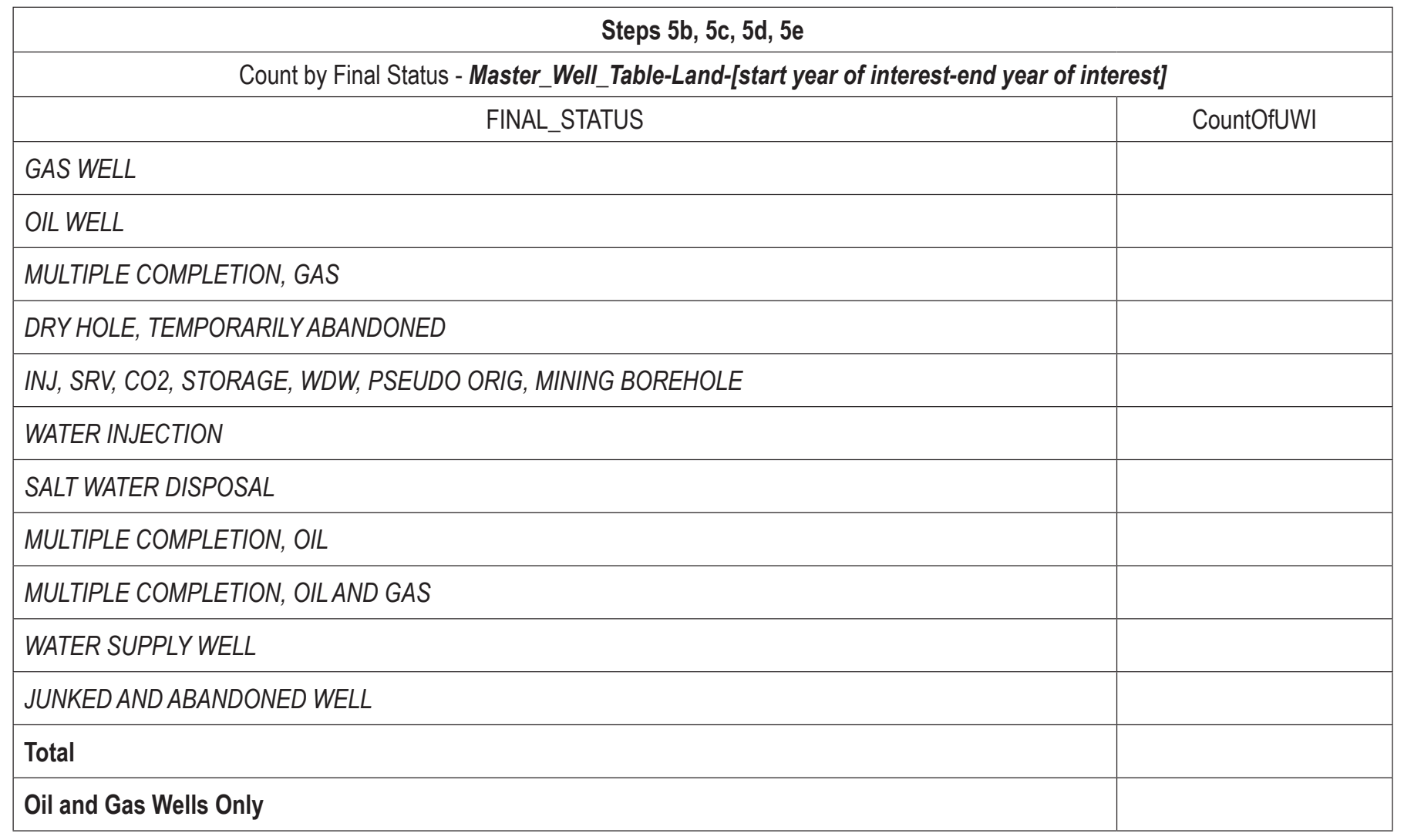


Table 4.9. Steps $5 b, 5 c, 5 d$, and $5 e$ count by HOLE_DIRECTION.

\begin{tabular}{|l|}
\hline \multicolumn{1}{|c|}{ Steps $5 \mathrm{~b}, 5 \mathrm{c}, 5 \mathrm{~d}, 5 \mathrm{e}$} \\
\hline \multicolumn{1}{|c|}{ Count by HOLE_DIRECTION - Master_Well_Table-Land-OilGas-[start year of interest-end year of interest] } \\
\hline VERTICAL NAME \\
\hline HORIZONTAL \\
\hline DIRECTIONAL \\
\hline PINNATE \\
\hline Total \\
\hline Vertical, Horizontal and Directional Oil and Gas Wells only \\
\hline
\end{tabular}

Table 4.10. Step $5 f$ record counts for land-based oil and gas horizontal, directional and vertical wells.

\begin{tabular}{|l|l|}
\hline \multicolumn{2}{|c|}{ Step $5 f$} \\
\hline$:: Q u e r y::$ & \\
\hline Record Count of Master_Well_Table-Land-OilGas-DHV-[start year of interest-end year of interest]: & \\
\hline$::$ Table:: & \\
\hline Record Count of Master Well Table-[start year of interest-end year of interest]: & \\
\hline
\end{tabular}

Table 4.11. Step 6 record counts for building Master Table-[start year of interest-end year of interest].

\begin{tabular}{|l|l|}
\hline \multicolumn{2}{|c|}{ Step 6} \\
\hline $\begin{array}{l}\text { Record Count of Master Well Table-[start year of interest-end year of interest] (FRAC or REFRAC, Onshore, Oil } \\
\text { or Gas Well, Horizontal Directional or Vertical): }\end{array}$ & \\
\hline$\because: Q u e r y::$ & \\
\hline Record Count of Unique UWls from Master Table-[start year of interest-end year of interest] & \\
\hline Record Count of Master TableQ-[start year of interest-end year of interest] & \\
\hline
\end{tabular}


Table 4.12. Step 7 record count of Master Table-[start year of interest-end year of interest].

\begin{tabular}{|c|c|}
\hline \multicolumn{2}{|l|}{ Step 7} \\
\hline Record Count of Master Table-[start year of interest-end year of interest] & \\
\hline $\begin{array}{l}\text { Does Master Table-[start year of interest-end year of interest] Only Include Records of COMP_YEAR=start year of } \\
\text { interest-end year of interest? }\end{array}$ & \\
\hline $\begin{array}{l}\text { Does Master Table-[start year of interest-end year of interest] Only Include Records of TRTM_TYPE=FRAC or } \\
\text { REFRAC? }\end{array}$ & \\
\hline $\begin{array}{l}\text { Does Master Table-[start year of interest-end year of interest] Only Include Records of HOLE_ } \\
\text { DIRECTION=HORIZONTAL or DIRECTIONAL or VERTICAL }\end{array}$ & \\
\hline
\end{tabular}

Table 4.13. Step 8 Master Table-[start year of interest-end year of interest] record count of TRTM_UNIT.

\begin{tabular}{|l|l|}
\hline \multicolumn{2}{|c|}{ Step 8 } \\
\hline \multicolumn{2}{|c|}{ Master Table-[start year of interest-end year of interest] Record Count of TRTM_UNIT } \\
\hline $\begin{array}{l}\text { Does Master Table-[start year of interest-end year of interest] (temporary query) only include records with a treatment } \\
\text { fluid amount in cubic meter units (CUM)? }\end{array}$ & $\begin{array}{l}\text { Record Count of Records for temporary query of Master Table-[start year of interest-end year of interest] of records with } \\
\text { treatment fluid amount? }\end{array}$ \\
\hline $\begin{array}{l}\text { Record Count of Treatments_w_values-[start year of interest-end year of interest] Query from Master Table[start } \\
\text { year of interest-end year of interest] only with records that have a TRTM_AMOUNT? }\end{array}$ & \\
\hline Record Count of Master Table w TRTM AMT-[start year of interest-end year of interest] & \\
\hline
\end{tabular}

Table 4.14. Step 9 record counts of unique wells that had treatment amounts.

\begin{tabular}{|l|l|}
\hline \multicolumn{2}{|c|}{ Step 9} \\
\hline Record Count of Unique Wells w TRTM_AMT-[start year of interest-end year of interest] & \\
\hline Record Count of Q-Master Wells Treatment Totals-[start year of interest-end year of interest] & \\
\hline
\end{tabular}

Table 4.15. Step 10 record counts of treatment totals by fluid.

\begin{tabular}{|l|l|}
\hline \multicolumn{2}{|c|}{ Step 10} \\
\hline Record Count of Q-Well Treatment Totals by Fluid-[start year of interest-end year of interest] & \\
\hline Record Count of Unique Wells Q-Well Treatment Totals by Fluid-[start year of interest-end year of interest] & \\
\hline Record Count of Master Well Treatment Totals by Fluid-[start year of interest-end year of interest] & \\
\hline
\end{tabular}





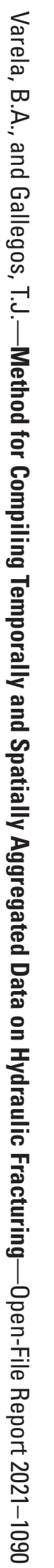

